\title{
Economía social, crisis económicas y reestructuración del estado de bienestar Caso español*
}

\author{
Social Economy, Economic Crisis and Welfare State Restructuration \\ Spanish Case
}

\author{
Economia Social, Crise Econômica e Reestruturação do Estado de Bem-Estar \\ Caso espanhol
}

\section{Elena Inglada Galiana ${ }^{1}$ \\ Emilio Pérez Chinarro ${ }^{2}$ \\ José Manuel Sastre Centeno ${ }^{3}$}

Recibido: 21 de enero de 2019

Aceptado: 31 de octubre de 2019

Publicado: 31 de enero de 2020

Cómo citar este artículo: Inglada Galiana, E., Pérez Chinarro, E. y Sastre Centeno, J.M. (2020). Economía social, crisis económicas y reestructuración del estado de bienestar. Caso español. Cooperativismo \& Desarrollo, 28(116)1-23. doi: https://doi.org/10.16925/2382-4220.2020.01.05

* Artículo de reflexion https://doi.org/10.16925/2382-4220.2020.01.05

1 Correo electrónico: elenaig@eco.uva.es Orcid.org/000-003-2139-7839

Doctorado en Gestión y Administración de Empresas. Doctora por la Universidad de Ciencias Económicas y Empresariales de Valladolid. España. Profesora del Departamento de Economía Financiera y Contabilidad en la Universidad de Valladolid. España.

2 Orcid: https://orcid.org/0000-0003-0831-6838

Doctor en Economía por la Universidad de Valladolid

Profesor de la Universidad de Valladolid -España

Correo electrónico: emilio.perez@uva.es / epchinarro@gmail.com

3 Doctorado en Gestión y Administración de Empresas. Doctor por la Universidad de Ciencias Económicas y Empresariales de Valladolid. España. Profesor del Departamento de Economía Financiera y Contabilidad en la Universidad de Valladolid.

Correo electrónico: manolo@eco.uva.es http://orcid.org/0000-0002-5440-9456 


\section{Resumen}

Objetivo: el presente artículo pretende establecer una vinculación histórica y actual entre la evolución del Estado de bienestar, la economía social y las crisis económicas. De este objetivo general se deduce otro objetivo más concreto: trazar los vínculos entre el estadillo de la recesión económica iniciada en 2008 y las consecuencias en el Estado de bienestar en España. Metodología: esta investigación se realiza con fuentes secundarias, mediante la revisión bibliográfica de aspectos teóricos del Estado del bienestar y la Economía Social. Se han analizado las consecuencias derivadas de la recesión, examinándose diferentes ámbitos de actuación correspondientes a las principales áreas que conforman la política social, fundamentalmente la vivienda, incluyéndose diversos indicadores -ejecuciones hipotecarias, desahucios o el PIB de las Comunidades Autónomas-. Para ello se ha trabajado a partir de una revisión bibliográfica de autores de referencia, revistas especializadas, sitios web y datos procedentes de fuentes gubernamentales (INE, Banco de España, entre otras). Resultados: el resultado advertido es que el Estado del bienestar ha experimentado transformaciones en sus interpretaciones y puntos de vista marcados por los heterogéneos contextos políticos económicos y sociales que ha vivido en los últimos años. En el presente, no es resultado de un único factor sino de un compendio de escenarios políticos, sociales y laborales que traspasan nuestras fronteras debido a la globalización. Conclusiones: se puede determinar que el futuro implica, necesariamente, una reestructuración del Estado del Bienestar dentro de las líneas generales de actuación que defiende la economía social.

Palabras clave: burbuja inmobiliaria, crisis económicas, déficit, Economía social, endeudamiento, Estado de Bienestar. Códigos JEL: R21, Economía urbana, rural, regional, inmobiliaria y de transporte: demanda de vivienda; D69, Economía del bienestar: otros; B55, Economía social

\section{Abstract}

Objective: This article aims to establish a historical and current link between the evolution of the welfare state, the social economy and economic crises. From this general objective, another more concrete objective can be deduced: to draw the links between the economic recession in 2008 and the consequences on the welfare state in Spain. Methodology: this research is carried out with secondary sources, through the literature review of theoretical aspects of the welfare state and the social economy. The consequences of the recession have been analyzed, examining different areas of action corresponding to the main areas that make up social policy, mainly housing, including various indicators - foreclosures, evictions or the GDP of the Autonomous Communities-.

Keywords: real estate bubble, economic crisis, deficit, social economy, indebtedness, welfare state. JEL Code: R21, Urban, rural, regional, real estate and transport economy: housing demand; D69, Welfare economics: others; B55, Social economy

\section{Resumo}

Objetivo: Este artigo tem como objetivo estabelecer um vínculo histórico e atual entre a evolução do estado social, a economia social e as crises econômicas. Deste objetivo geral, outro objetivo mais concreto pode ser deduzido: estabelecer os vínculos entre a recessão econômica em 2008 e as conseqüências para o estado social da Espanha. Metodologia: esta pesquisa é realizada com fontes secundárias, através da revisão da literatura sobre aspectos teóricos do estado de bem-estar e da economia social. As consequências da recessão foram analisadas, examinando diferentes áreas de ação correspondentes às principais áreas que compõem a política social, principalmente a habitação, incluindo vários indicadores - execuções duma hipoteca, despejos ou o PIB das Comunidades Autônomas -.

Palavras-chave: bolha imobiliária, crise econômica, déficit, economia social, endividamento, estado assistencialista. Códigos JEL: R21, Economia urbana, rural, regional, imobiliária e de transporte: demanda habitacional; D69, Economia do bem-estar: outros; B55, Economia social 


\section{Introducción}

La economía social, las crisis económicas y la reestructuración del Estado del Bienestar son tres factores que, en los primeros años del siglo XXI, han convulsionado los cimientos de un sistema económico que, a finales del siglo anterior, parecía disponer de la fórmula idónea para un desarrollo sostenido. Las crisis económicas, durante el siglo XX se habían sucedido de manera periódica seguían produciéndose, pero los controles las atenuaban y hasta las evitaban. La economía social parecía triunfar en una sociedad económicamente descompensada, con fuertes bolsas de pobreza y grupos con grandes beneficios. El Estado del Bienestar había logrado, en los países occidentales por lo menos, un cierto equilibrio asentado en una redistribución de la riqueza que, en algunos aspectos, especialmente los sanitarios, cubría prácticamente a toda la población.

Todo ello se vino abajo inopinadamente. Una crisis provocada por la burbuja inmobiliaria y prácticas bancarias cuanto menos cuestionables, devinieron en una caída de todos los indicadores económico y sociales. El Estado del Bienestar se hundió al tiempo que las grandes instituciones capitalistas: bolsa, finanzas y estructura bancaria. La economía social y el Estado del Bienestar dejaron paso al simple rescate de economías nacionales amenazadas por la bancarrota -default o incumplimiento de las obligaciones de pago-. El Estado del Bienestar fue sacrificado, en muchos países occidentales, entre ellos España, en función de las necesidades de ahorro y el cumplimiento de los compromisos contraídos. Buena parte del mismo ha sido desmontado para reducir los gastos del Estado y mantenerse dentro de los límites de déficit que las autoridades monetarias internacionales consideraron para mantener a flote las economías en crisis.

\section{La economía social}

La economía es social por definición, por cuanto es un producto de la sociedad, pero cuando se habla de economía social (ES en adelante) la adjetivación implica un tipo más concreto de economía. Aunque las definiciones y factores que debe contener el concepto de ES varían según los autores y las escuelas doctrinales, algunos de ellos son comunes a todas: la preeminencia de la persona sobre el capital, la preponderancia del objeto social sobre los beneficios particulares, la concurrencia entre los intereses particulares y los comunes, el respeto por los principios de solidaridad y responsabilidad, y promover el desarrollo sostenible. 
Aun cuando el concepto aparece a principios del siglo XX en Francia ${ }^{4}$, no es hasta después de la Segunda Guerra Mundial, en los años setenta, en que se populariza, también en el país galo, y tiene como elementos principales, en dichas fechas, su orientación no lucrativa y el componente social ${ }^{5}$. Todo ello la relaciona con el movimiento cooperativista ${ }^{6}$, que aparece y se desarrolla en Francia en el siglo XIX como consecuencia de una reacción contra el capitalismo salvaje de la primera revolución industrial (Pineda et al., 1994)7. Esta relación entre el cooperativismo y la ES destaca aún más por cuanto los países con fuertes tendencias cooperativas, entre ellos España, son en los que con mayor fuerza y extensión han surgido las entidades acogidas al llamado tercer sector o economía social. Monzón y Chaves han manifestado que:

El sistema de valores y los principios de actuación de las asociaciones populares, reflejados en el cooperativismo histórico, son los que han servido de base al concepto moderno de ES, que se estructura en torno a tres grandes familias de organizaciones: las cooperativas, las mutuas y las asociaciones, con la reciente incorporación de las fundaciones. (Monzón y Chaves, 2012, p.13)8.

Cierto es que el término tercer sector es algo ambiguo y suele llevar a equívocos. vocablo es de origen anglosajón y designa las empresas o entidades no lucrativas cuyos beneficios se deben reinvertir en la propia entidad y sus actividades. En este concepto se integran plenamente, y los americanos lo consideran así, entidades como

4 Incluso desde antes, por cuanto desde la antigüedad ha habido autores que se han preocupado por organizar la sociedad de una manera más justa y humana, por suprimir las desigualdades y buscar un sistema de redistribución de la riqueza de manera igualitaria; por ejemplo: La Republica de Platón (428-347 a. de C); Utopía de Tomás Moro (1480-1535); La Nueva Atlántida de Francis Bacon (1561-1626) o El Viaje a Icaria de Etienne Cabet (1788-1856).

5 Aparece en un documento publicado por el Comité Nacional de Enlace de las Actividades Mutualistas, Cooperativas y Asociativas (CNLAMCA) titulado "Charte de l'economie sociale" (Carta de Economía social)

6 Aranzadi (1976) define cooperativa como: "[...] una asociación de personas que organizan y administran empresas económicas basándose en el esfuerzo mutuo, que atienden los intereses socioeconómicos de los socios siempre y cuando no se oponga a los intereses generales de la comunidad, y que se rigen por determinadas normas de carácter equitativo y de esencia universal, por supuesto susceptibles de evolucionar.", que es prácticamente la definición de la economía social.

7 "No obstante, de la Revolución Industrial también nacieron alternativas opuestas a ella, como las ideas y realizaciones cooperativas del siglo XIX que aparecen como consecuencias de los efectos sociales, económicos y políticos, causados precisamente por el cambio en la concepción del mundo y de lo que significó dicha revolución"

8 Se trata del Informe elaborado para el Comité Económico y Social Europeo por el Centro Internacional de Investigación e Información sobre la Economía Pública, Social y Cooperativa (CIRIEC). 
clubs deportivos o sindicatos, incluidos partidos políticos o asociaciones profesionales. Entidades que, evidentemente, en la versión europea de ES no se considerarían englobadas dentro de dicho concepto. Tampoco la consideración de no lucrativo es necesaria en esta última perspectiva. El lucro no es tan importante al considerar la ES como el destino o reparto de dicho lucro. Es más, el beneficio se considera necesario teniendo en cuenta que, de otra manera, es difícil rivalizar en un mercado altamente competitivo (Gomá et al., 2001).

La ES nace como una manifestación de la sociedad civil que quiere intervenir en el desarrollo de la organización económica de su espacio vital e implicarse en la organización del Estado de bienestar, buscando el mejor equilibrio entre los intereses de los distintos agentes sociales y la mayor justicia retributiva de los beneficios de las entidades, pero también de la sociedad. Todo ello con la utilización más eficiente de los recursos, de manera que sean aprovechados por la actual generación, pero se preserven los derechos de las futuras generaciones a disponer y disfrutar de ellos (Vázquez et al., 2013).

A continuación, en la tabla 1, quedan recogidos los modelos y el número de Empresas de la ES en España.

Tabla 1. Modelos empresas de ES en España.

\begin{tabular}{|c|c|c|c|c|c|c|c|c|}
\hline \multicolumn{9}{|c|}{ Número de entidades de la ES. } \\
\hline Cooperativas & 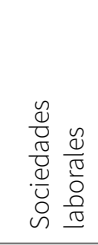 & 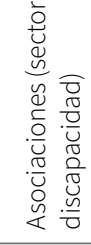 & 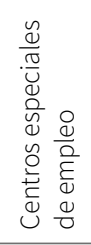 & 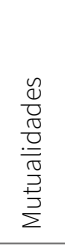 & 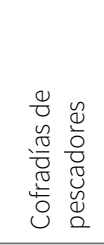 & 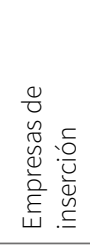 & 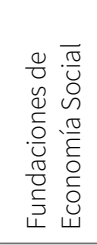 & 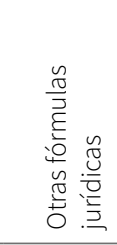 \\
\hline 22.206 & 10.471 & 8.164 & 450 & 373 & 132 & 206 & 92 & 3.784 \\
\hline
\end{tabular}

Fuente: tomada de $\mathrm{N} .^{\circ}$ de entidades de Economía Social, por Cepes, 2018

La doctrina coincide mayoritariamente en que la ES es "una apuesta de futuro para la creación de una sociedad del bienestar" (García, 2004), lo cual implica que la sociedad, como fuerza emergente en el marco directo de la política, quiere un nuevo modelo participativo y, especialmente, un mayor control de los recursos con que se cuenta y de aquellos que se producen en la economía de cada territorio. En este contexto, las sociedades civiles se han constituido en motores de dos grandes movimientos sociales: las nuevas formas de participación cívica y la conformación de estructuras de solidaridad (Rodríguez, 2005). A este respecto, hay que destacar que España ha sido 
el primer país europeo que aprobó una Ley de ES, en $2011^{9}$. Esta ley, en su preámbulo, además de hacer una relación de las empresas que considera características de la economía social, contempla la importancia de las organizaciones sociales a las que considera interlocutoras en lo que respecta a dicha economía social. En el artículo 2 de dicha ley define la económica social como el "conjunto de las actividades económicas y empresariales, que en el ámbito privado llevan a cabo aquellas entidades persiguen bien el interés colectivo de sus integrantes, bien el interés general económico o social, o ambos." Además, en el artículo 4, establece la primacía de las personas y del fin social sobre el capital ${ }^{10}$. De igual manera y con unos conceptos muy parecidos, desde 2011 se han aprobado, en muchos países de la UE, legislaciones sobre economía social, existiendo incluso en el mismo Parlamento Europeo un intergrupo sobre economía social. Se han elaborado, dentro de la Unión Europea, todo un conjunto de directrices y directivas sobre la materia, así como informes publicados por el Comité Económico y Social Europeo (CESE) sobre las empresas de ES y su contribución a los objetivos de la política comunitaria.

Uno de los problemas que se plantea alrededor de la ES es su relación con el sistema de cuentas nacionales. A este respecto, se consideran dos subsectores: el subsector de mercado o empresarial ${ }^{11}$ y el subsector productor no de mercado. Para ambos subsectores, la definición de ES es la misma: "son organizaciones de personas que llevan a cabo una actividad con el objetivo principal de satisfacer las necesidades de las personas y no de retribuir a inversores capitalistas" (Monzón y Chaves, 2012, pp.23-24).

Los dos subsectores tienen unas características comunes: son privados, no están controlados por el sector público; por lo general tienen personalidad jurídica; poseen autonomía de decisión, o sea, son independientes respecto a dotarse de los órganos de gobierno; son libres para unirse o no entre ellos; los beneficios se reparten entre los socios no en función al capital invertido o a las aportaciones de los socios,

9 Ley 5 de 2011 de economía social.

10 El artículo $5^{\circ}$ explicita cuáles son el tipo de entidades que considera la Ley como de economía social: cooperativas, mutualidades, fundaciones y asociaciones que lleven a cabo actividad económica, también las sociedades laborales, cofradías de pescadores, entre otras.

11 Según el Informe citado del Comité Económico y Social Europeo: "La expresión «empresa» se utiliza principalmente para designar a las organizaciones microeconómicas cuya principal fuente de recursos proviene del mercado (la mayoría de las cooperativas, las mutuas, las empresas sociales y otras empresas). Es menos común, aunque no imposible, utilizar la denominación de 'empresa para referirse a otras organizaciones microeconómicas de la ES cuyos recursos monetarios provienen principalmente de fuera del mercado, en forma de donaciones, cuotas de socios, rentas de la propiedad o subvenciones (la mayoría de las asociaciones y fundaciones). Estos productores no de mercado también llevan a cabo actividades económicas que entran dentro del ámbito del análisis de las cuentas nacionales." (Monzón y Chaves, 2012, p. 23) 
sino en función de sus actividades o transacciones con la organización; son organizaciones de personal, no de capital, porque desarrollan las actividades económicas para satisfacer las necesidades de las personas y las familias. Trabajan con capital, pero no para el capital y son organizaciones democráticas (Monzón y Chaves, 2012).

Es interesante, respecto a los países miembros de la Unión Europea, los resultados de la encuesta sobre la aceptación que la ES tiene en dichos países, realizada por el Comité Económico y Social Europeo.

1) Países en los que el concepto de ES está ampliamente aceptado: España, Francia, Portugal, Bélgica, Irlanda y Grecia. El concepto está ampliamente aceptado por estamentos sociales como el político, intelectual, universitario o científico.

2) Países en los que el concepto de ES goza de un nivel moderado de aceptación: Italia, Chipre, Dinamarca, Finlandia, Luxemburgo, Suecia, Letonia, Malta, Polonia, el Reino Unido, Bulgaria e Islandia. Se trata de una aceptación moderada y parcial, coexiste el concepto con otros parecidos, pero no iguales.

3) Países en los que existe un reconocimiento escaso o nulo del concepto de economía social: Austria, la República Checa, Estonia, Alemania, Hungría, Lituania, Países Bajos, Eslovaquia, Rumanía, Croaciay Eslovenia. Utilizan más "sector no lucrativo", "sector voluntario" y "organización no gubernamental", sobre el de economía social, aun cuando el hecho es el mismo.

En resumen, la ES es un intento de la sociedad actuando como grupo organizado y con objetivos esencialmente sociales, para cambiar un sistema, el capitalista, por otro basado en una redistribución de los beneficios que beneficien a la sociedad en su conjunto, no a un grupo determinado. Es un concepto innovador de la economía no tanto porque sea nuevo, sino porque ha sido renovado y adaptado a una sociedad actual mucho más dinámica, más informada y con mayores conocimientos. La UE es uno de los territorios donde con mayor fuerza incide la ES y en la que mayores logros ha alcanzado, si bien, se ha enfrentado en los últimos años con un nuevo factor: la crisis económica, que ha desestabilizado todo el Estado de Bienestar creado desde el fin de la Segunda Guerra Mundial, basado en buena parte en la ES. La pregunta es ¿qué ocurre con la ES y el Estado de Bienestar después de la crisis económica? 


\section{El Estado del Bienestar}

Para una parte de la doctrina, el Estado del Bienestar es una corrección de la mala distribución de la riqueza, de manera que la acumulación de capital en unos pocos sea en parte socializada por el Estado y repartida, a través de actividades sociales como el deporte (López-Cozar, Riede y del Arco, 2015), las sanitarias o las culturales, por ejemplo, entre los menos favorecidos (Berzosa, 2003; de Paz, 2003 y Rodríguez Cabrero, 2004). En este contexto, los orígenes del Estado de Bienestar en el sentido moderno aparecen con la Revolución Industrial del siglo XVIII y con el liberalismo, que son las causas de una mala distribución de la riqueza que diferencia, cada vez más, a los ricos de los pobres. Cortina señalan que:

Del Estado de Bienestar al Estado de justicia" que hace hincapié en la relevancia de comprender el asunto de los derechos humanos en su vertiente sociopolítica. Esta autora, señala que "Ios mínimos de justicia son cosa de los Estados, mientras que el bienestar págueselo cada quien de su peculio. La cuestión estriba entonces en delimitar qué necesidades y bienes básicos han de considerarse como mínimos de justicia que un Estado social de derecho no puede dejar insatisfechos sin perder su legitimidad. (Cortina, 1994, citado en Velasco Criado, 2001, p. 294).

El concepto de bienestar aparece en el DRAE en tres acepciones: "Conjunto de las cosas necesarias para vivir bien; vida holgada o abastecida de cuanto conduce a pasarlo bien y con tranquilidad; estado de la persona en el que se le hace sensible el buen funcionamiento de su actividad somática y psíquica". La primera y segunda son complementarias entre ellas, y si la primera se refiere más a lo material la segunda entra en un terreno más espiritual. El bienestar, pues, en estas dos primeras definiciones, está íntimamente ligado a no tener carencias materiales ni preocupaciones por posibles carencias, centrándose en la tranquilidad como un objetivo a alcanzar. La tercera acepción entra en el campo de la medicina, por cuanto entiende que el bienestar es el correcto funcionamiento del cuerpo y el espíritu en armonía. Esta definición del DRAE no está muy lejos de la que propone la OMS para la salud: "un estado de completo bienestar físico, mental y social, y no solamente la ausencia de afecciones o enfermedades" Con ello se identifica bienestar con lo físico, lo mental y lo social. Y añade la OMS: "El goce del grado máximo de salud que se puede lograr es uno de los derechos fundamentales de todo ser humano 
sin distinción de raza, religión, ideología política o condición económica o social" (OMS, 2006, p. 31). El bienestar es pues un conjunto de factores materiales, espirituales, de salud, economía, sociales y familiares, entre otros, conforman un tipo de vida considerada deseable (Ferrari y Cebey, 2006).

Esping-Andersen llevó a cabo un acopio empírico y sistémico, creando una clasificación del Estado de Bienestar, que se ha convertido en universal. Así, se tienen los siguientes modelos (Esping-Andersen, 2001; Navarro Ruvalcaba, 2006):

- Modelo liberal o residual: este tipo se particulariza por una política liberal, una economía capitalista y políticas sociales residuales. Este modelo acata el mecanismo de mercado como garante del bienestar, fomentándose la protección social privada, quedando la pública en una posición secundaria que atiende únicamente escasas situaciones de exclusión. Es decir, este modelo se enfoca en los marginados mientras que los que pertenecen a la población que trabaja se ampara con seguros privados o de empresas y esto supone un elevado grado de desigualdad. Estados Unidos es un claro ejemplo de este modelo.

- Modelo conservador-corporativista: basado históricamente en las antiguas formas feudales de relaciones entre clases, se fundamenta en un concepto de cohesión social que deriva de la división en grupos que han de proteger a sus individuos, actuando el Estado como garante final en caso de fallar las ayudas del mencionado grupo o de otras instituciones intermedias - como la iglesia o asociaciones voluntarias-, a los miembros que lo necesiten. Es la visión que predomina en Europa continental y como característica principal podría decirse que tiene una visión mutualista del régimen de bienestar. Las prestaciones sociales se brindan por grandes corporaciones profesionales que el Estado crea y supervisa. En este modelo la seguridad social es obligatoria y predominante.

- Modelos socialdemócratas o universales: se particulariza por políticas de clase, políticas sociales redistributivas y una económica social. Se trata de un tipo generoso con respecto a las prestaciones sociales del Estado. El derecho a las mismas, por lo general, está enfocado a la ciudadanía y no al tipo de contribuciones económicas que hacen los ciudadanos; los servicios los brinda fundamentalmente el sector público. El caso paradigmático se encuentra en los países nórdicos. Por último, Rubio Lara que señala que las prestaciones sociales se han de entender como un derecho del ciudadano y la aplicación de los servicios sociales no ha 
menoscabado de ningún modo el desarrollo económico en los países escandinavos.

En las ciencias sociales y, especialmente, en la literatura especializada en el tercer sector y la empresa social, la clasificación de Esping-Andersen ha tenido una enorme relevancia puesto que manifiesta tres heterogéneos marcos históricos, jurídicos y también políticos en el que actúan dichas organizaciones. En la tabla 2 quedan resumidos los modelos referidos y sus características principales.

Tabla 2. Modelos de Estado de Bienestar e Indicadores de Política de Bienestar.

\begin{tabular}{llll}
\hline \multicolumn{1}{c}{$\begin{array}{c}\text { Elementos del régimen } \\
\text { e impactos }\end{array}$} & \multicolumn{1}{c}{ Conservador ${ }^{12}$} & \multicolumn{1}{c}{ Liberal $^{13}$} & Socialdemócrata \\
\hline Cobertura de la población & Ocupacional & Selectivo & Universal \\
\hline Papel del mercado en el bienestar & Bajo & Alto & Alto \\
\hline Población objetivo. & Individuo (empleado) & Los pobres & Toda la ciudadanía \\
\hline Grado de desmercantilización & Medio & Bajo & Alto \\
\hline Grado de desfamilización & Bajo & Bajo & Alto \\
\hline Grado de remercantilización & Bajo & Medio & Alto \\
\hline Redistribución & Bajo & Bajo & Alto \\
\hline Reducción de la pobreza & Medio & Bajo & Alto \\
\hline
\end{tabular}

Fuente: elaboración propia a partir de Comparative and Historical Studies of Public Policy and the Welfare State, de Hicks y Esping-Andersen, 2005.

En una sociedad desarrollada, las bases del bienestar social son la familia que actúa como una sociedad de ayuda mutua; el mercado, que permite crear riqueza, y el Estado que debe redistribuirla. En este trinomio se basa el bienestar social (Montagut, 2004 y Rodríguez, 2004). Es el Estado quien debe proporcionar los marcos adecuados a sus ciudadanos para que estos participen en el Estado de Bienestar que su país pueda proporcionarles. Es una aspiración entroncada con las viejas reclamaciones de los obreros en la fase más negra de la Revolución Industrial y que se incluyeron en los movimientos revolucionarios de finales del siglo XIX y principios del XX, recogidas por los partidos revolucionarios, desde los anarquistas a los socialistas pasando por los comunistas. La demanda de bienestar fue uno de los motivos de las tensiones sociales que Keynes estudió para lanzar su propuesta del Estado de Bienestar.

12 Francia, Italia, España, Alemania, Austria, Bélgica, Japón, y Portugal.

13 Estados Unidos, Irlanda, Canadá, Reino Unido, Australia y Nueva Zelanda.

14 Países nórdicos. 
Uno de los problemas que se plantean respecto al Estado del Bienestar es que cada ciudadano tiene su idea del mismo, es decir, se trata de un concepto muy subjetivo y, en muchos casos, coyuntural (Calveiro, 2015). No se trata sólo de una postura individual, sino que el concepto de bienestar también depende del país, de la región y de las peculiaridades del grupo social que se trate. Lo que en un territorio puede considerarse un bajo nivel de bienestar en otro será un nivel inalcanzable. Por lo tanto, el Estado tiene que averiguar y evaluar el grado y tipo de bienestar que desean sus ciudadanos e intentar ofrecérselo siempre que la economía del país lo permita (Montagut, 2004; Rodríguez, 2004). Por ejemplo, en España uno de los factores más destacados que ponen en tela de juicio el Estado del Bienestar nacional es la problemática de los desahucios. No se trata tanto de un problema económico, pues el Estado, con alguna presión e incluso con poco dinero, podría superar el problema que representan los desahucios. Es un problema individual de grandes dimensiones desde la perspectiva económica y ética; desde la primera y a nivel macroeconómico podría solucionarse fácilmente. El problema de tipo legal, creado por una legislación anticuada que los gobiernos, presionados por la banca se resisten a cambiar. Es pues un problema coyuntural a nivel general, desde luego un problema social y desgarrador a nivel particular. Prueba de ello son las cifras que se recogen en la tabla 3 y 4 , en donde se exponen los últimos datos disponibles de las ejecuciones hipotecarias y desahucios brindados por el Banco de España y el INE.

Tabla 3. Ejecuciones hipotecarias y desahucios.

\begin{tabular}{|c|c|c|c|c|c|c|}
\hline & \multicolumn{3}{|c|}{2015} & \multicolumn{3}{|c|}{2014} \\
\hline & 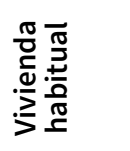 & 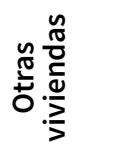 & 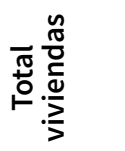 & 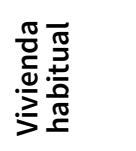 & 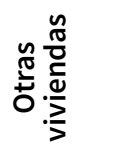 & 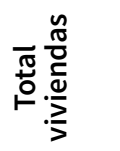 \\
\hline Número de hipotecas sobre viviendas & 5.803 .699 & 581.324 & 6.385 .023 & 5.828 .427 & 629.701 & 6.458 .128 \\
\hline Entregas de viviendas & 29.327 & 7.602 & 36.929 & 30.056 & 8.346 & 38.402 \\
\hline Voluntarias & 15.500 & 3.490 & 18.990 & 19.406 & 2.881 & 22.287 \\
\hline Daciones en pago & 13.193 & 2.982 & 16.175 & 16.489 & 1.994 & 18.483 \\
\hline Entregas judiciales & 13.827 & 4.112 & 17.939 & 10.650 & 5.465 & 16.115 \\
\hline De vivienda vacía & 12.925 & 3.902 & 16.827 & 9.521 & 5.234 & 14.755 \\
\hline De vivienda ocupada (desahucios) & 902 & 210 & 1.112 & 1.129 & 231 & 1.360 \\
\hline $\begin{array}{l}\text { Con intervención de las Fuerzas del } \\
\text { orden. }\end{array}$ & 6 & 8 & 14 & 20 & 5 & 25 \\
\hline
\end{tabular}

Fuente: tomada de Nota informativa sobre los procesos de ejecución hipotecaria sobre viviendas, por el Banco de España, 2016, p.3. 
Tabla 4. Certificaciones por ejecuciones hipotecarias iniciadas e inscritas. Primer trimestre 2018.

\begin{tabular}{|c|c|c|c|c|}
\hline CC.AA. & Total, fincas & Viviendas & $\begin{array}{l}\text { Viviendas } \\
\text { personas físicas }\end{array}$ & $\begin{array}{c}\text { Viviendas } \\
\text { personas jurídicas }\end{array}$ \\
\hline Andalucía & 2.453 & 1.358 & 722 & 636 \\
\hline Aragón & 366 & 160 & 32 & 128 \\
\hline Asturias, Principado de & 351 & 123 & 75 & 48 \\
\hline Balears, Illes & 208 & 132 & 61 & 71 \\
\hline Canarias & 589 & 287 & 163 & 124 \\
\hline Cantabria & 363 & 145 & 19 & 126 \\
\hline Castilla y León & 778 & 253 & 84 & 169 \\
\hline Castilla - La Mancha & 680 & 353 & 80 & 273 \\
\hline Cataluña & 2.688 & 1.336 & 550 & 786 \\
\hline Comunidad Valenciana & 2.812 & 1.240 & 428 & 812 \\
\hline Extremadura & 305 & 143 & 60 & 83 \\
\hline Galicia & 240 & 90 & 38 & 52 \\
\hline Madrid, Comunidad de & 1.024 & 504 & 202 & 302 \\
\hline Murcia, Región de & 723 & 297 & 58 & 239 \\
\hline Navarra, Comunidad Foral de & 124 & 33 & 14 & 19 \\
\hline País Vasco & 120 & 36 & 34 & 2 \\
\hline Rioja, La & 354 & 204 & 13 & 191 \\
\hline TOTAL & 14.183 & 6.699 & 2.638 & 4.061 \\
\hline
\end{tabular}

Fuente: Estadística sobre Ejecuciones Hipotecarias (EH), por INE, 2018, p.4.

Todo ello está agravado por una estructura asimétrica entre las CC.AA. españolas, con aportaciones muy diferentes al PIB español y que, sin embargo, aspiran todas al mismo Estado de Bienestar. Diferencias que van desde un 19,2 \% para Cataluña y un $18,9 \%$ para Madrid, y un 0,1 \% para Melilla y Ceuta. En la tabla 5, se puede ver que comunidades son las que originan más riqueza.

Tabla 5. Aportación de cada Comunidad Autónoma al PIB.

\begin{tabular}{ccc}
\hline Posición & Comunidad Autónoma & PIB (\%) \\
\hline 1 & Cataluña & 19,2 \\
\hline 2 & Madrid, Comunidad de & 18,9 \\
\hline 3 & Andalucía & 13,3 \\
\hline 4 & Comunitat Valenciana & 9,3 \\
\hline 5 & País Vasco & 6,2 \\
\hline 6 & Galicia & 5,2 \\
\hline 7 & Castilla y León & 4,9 \\
\hline & & continúa
\end{tabular}




\begin{tabular}{ccc}
\hline Posición & Comunidad Autónoma & PIB (\%) \\
\hline 8 & Canarias & 3,8 \\
\hline 9 & Castilla-La Mancha & 3,4 \\
\hline 10 & Aragón & 3,1 \\
\hline 11 & Murcia, Región de & 2,6 \\
\hline 12 & Balears, Illes & 2,6 \\
\hline 13 & Asturias, Principado de & 2,0 \\
\hline 14 & Navarra, Comunidad Foral de & 1,7 \\
\hline 15 & Extremadura & 1,6 \\
\hline 16 & Cantabria & 1,1 \\
\hline 17 & Rioja, La & 0,7 \\
\hline 18 & Ceuta & 0,1 \\
\hline 19 & Melilla & 0,1 \\
\hline
\end{tabular}

Fuente: PIB de España por Comunidades Autónomas, por INE, 2017.

En las sociedades desarrolladas occidentales, el Estado de Bienestar aparece en el momento en que los gobiernos asumen la tarea de intervenir en las condiciones de vida de sus ciudadanos, por considerar que la importancia de las mismas las convierte en una obligación del Estado, que debe satisfacerlas, controlarlas y mejorarlas. Para ello precisa, en primer lugar, describir cuáles son estas prioridades vitales, las satisfacciones que quiere el ciudadano y cuál es su sensación de bienestar. Por otro lado, se debe crear un instrumento de medida estandarizado del bienestar social que permita comprobar el avance o retroceso del grado de bienestar de la población, cuáles son las diferencias entre los grupos respecto al avance hacia el bienestar y si las estrategias de política social del gobierno son eficaces o no (Díez Collado, 1994). En la tabla 6 se indican las principales particularidades del régimen de bienestar liberal.

Tabla 6. Características del régimen de bienestar liberal.

\begin{tabular}{lllc}
\hline & $\begin{array}{c}\text { Régimen } \\
\text { liberal }\end{array}$ & Variables significativas & $\begin{array}{c}\text { Familia de naciones } \\
\text { angloparlantes }\end{array}$ \\
\hline Papel de: & Marginal & Tasa de fecundidad. & Alto \\
- Familia. & central & Gasto de educación. & Bajo \\
- Mercado. & Marginal & Carga fiscal global. & Bajo \\
\hline - Estado. & & & continúa
\end{tabular}




\begin{tabular}{lllc}
\hline & $\begin{array}{c}\text { Régimen } \\
\text { liberal }\end{array}$ & Variables significativas & $\begin{array}{c}\text { Familia de naciones } \\
\text { angloparlantes }\end{array}$ \\
\hline Estado de Bienestar: & & Impuestos sobre renta y beneficios. & Alto \\
- Modo de solidaridad. & Individual & Total, de gastos. & Bajo \\
- Dominante. & Mercado & Población activa femenina. & Medio \\
- Locus de solidaridad. & Mínimo & Población activa masculina. & Alto \\
- Grado de & & Empleo público. & Bajo \\
desmercantilizacion. & & Trasferencias de la seguridad social. & Bajo \\
\hline
\end{tabular}

Fuente: elaboración propia adaptada de The English-Speaking Countries, por Castles, 2010

España, junto a Grecia, Italia y Portugal, forma parte de lo que se ha llamado bienestar mediterráneo o régimen mediterráneo de bienestar. Cierto que hay muchas similitudes no sólo culturales y sociales entre los cuatro países, sino que también han compartido una historia, hasta cierto punto análoga, durante el siglo XX. La religión ha tenido una significación especial en todos ellos, constituyendo un factor estructurado respecto a la sociedad. Asimismo, han desarrollado unos lentos y no muy brillantes procesos de industrialización hasta alcanzar ciertas cuotas que les han permitido relegar la dependencia de la agricultura, aunque no han alcanzado las cuotas de otros países europeos. Experimentaron una rápida modernización, pero tarde, lo que les impidió llegar a tiempo para alcanzar la denominada Edad de Oro del welfare (1945-1975). Y se han visto, aun cuando con diferentes matices, muy comprometidos con la crisis que estalló en la segunda mitad de la década pasada (Díez Collado, 1994).

El régimen mediterráneo del bienestar se sustenta en la familia, que en la cultura mediterránea ha actuado siempre como una seguridad social nuclear. Toda la estructura de las políticas sociales de estos países se sustenta en último término en la familia. Los miembros aportan su apoyo material y afectivo consolidando un Estado de Bienestar que proporciona seguridad, atención y tranquilidad para toda la unidad familiar. Esto proporciona un alto grado de satisfacción que se refleja en los indicadores del Estado del Bienestar, pero al tiempo es la causa de que los gobiernos de estos países realicen pocas inversiones en los elementos político-sociales que componen dicho bienestar.

Este modelo está muy lejos del modelo nórdico y aunque éste sea más generoso y avanzado que el mediterráneo, lo cierto es que sus objetivos básicos fueron otros. Su objetivo fue reducir o mantener las desigualdades sociales en su punto más bajo posible, o sea, lograr el bienestar social de todos sus ciudadanos independientemente de la situación económica de cada uno de ellos. Esto, consecuentemente, lleva a una política social con coberturas universales que comprenden a todos los ciudadanos. 
No se trata tanto de un modelo que cubra las necesidades mínimas de una clase o un grupo social marginado, sino un modelo que trata de premiar al ciudadano por vivir en un país rico. Este tipo de políticas de ámbito universal están sujetas a fuertes ingresos de los países y una población relativamente pequeña.

Diferente es el sistema continental, o profesional, también conocido como sistema bismarkiano (Ministerio de AA.PP., 2008), por ser dicho estadista alemán quién lo decretó en 1889. La base son un conjunto de seguros de riesgo relacionados con los trabajos. En principio sólo se beneficiaban los trabajadores, aunque éste es un modelo que ha sido muy reformado y adaptado a las necesidades de la población en distintas ocasiones. Las cotizaciones dependen del salario, así como las prestaciones. Cotizan los empleados y los empresarios, dependiendo del tipo de seguro. Es un sistema algo complicado debido a sus antecedentes y al enfrentamiento que propició entre la Iglesia y el Estado, debido a que según la Iglesia, el Estado invadía sus atribuciones. Está muy condicionado por la ética del trabajo protestante, considerando que la satisfacción de las necesidades sociales debe estar en función del rendimiento en el trabajo y la productividad de cada uno. En definitiva, se sitúa en el polo opuesto al modelo nórdico universalista.

El modelo español, el modelo mediterráneo, se fundamenta en tres factores:

- Es un modelo profesional, aunque con tendencia a la universalización, como por ejemplo respecto a la sanidad.

- De base contributiva, o sea que se financia con las cotizaciones sociales de empresarios y trabajadores.

- Lo gestiona el Estado.

El problema del sistema español de Seguridad Social no es el modelo en sí mismo, que parece suficientemente bueno, sino la capacidad financiera, a medio y largo plazo, del mismo (Tortuero y Águila, 2004).

Es necesario hacer referencia al trabajo de Martínez (2013), quien analiza la situación del Estado de Bienestar a nivel europeo estableciendo una comparativa entre los distintos modelos. Para empezar, indica que los objetivos que secunda el Estado de Bienestar son brindar seguridad social y económica a la población, mermar las desigualdades, así como, desarrollar políticas para eliminar la pobreza. Señala que es un sistema económico que "permitiría al Estado corregir los desequilibrios económicos y compensar las insuficiencias del gasto privado" (Martínez, 2013, p. 208). Establece una selección en cuanto a las diferencias entre los países mediterráneos, los cuales prefieren un mayor amparo del trabajo, de desempleo, los nórdicos, que 
contrariamente amparan poco al trabajador pero los que están desempleados reciben casi todos los subsidios, los continentales que evidencian en ambas variables un grado ligeramente más alto que la media europeo y, por último, arguye que los anglosajones fundamentan su protección en los subsidios de desempleo con un grado muy bajo de amparo el empleado. Al respecto Martínez señala que:

Todos los indicadores sociales muestran que, en los últimos veinte años, la calidad de vida y el bienestar social se han deteriorado de forma generalizada en todo el mundo, afectando tanto a países industrializados, como subdesarrollados, producto entre otros factores, de la globalización; creando un mundo de ganadores y perdedores unos pocos hacia el camino rápido de la prosperidad y la inmensa mayoría condenada a una vida de miseria y desesperación. Ante tal situación, vale la pena preguntarse si estamos ante la crisis del Estado de Bienestar, economía de mercado o capitalismo de amigotes y clases dominantes. De lo que, si podemos estar seguros, es que un nuevo fantasma recorre Europa, que amenaza al mundo globalizado con una catástrofe de dimensiones insospechadas; de no tomarse las medidas necesarias a lo inmediato (Martínez, 2013, p. 203).

\section{Crisis económicas}

El boom inmobiliario se inicia en 1996, año en que se construyen 287000 viviendas que eran, más o menos, las necesidades del país y los precios de las viviendas estaban, en líneas generales, dentro de las medias europeas. El metro cuadrado de vivienda libre se vendía a 685 euros y el coste total de la vivienda venía a ser los ingresos de un hogar en tres años y medio.

Diez años después, en 1996, se construyeron 760179 viviendas, más del doble de las necesidades del país según el índice de crecimiento de hogares y teniendo en cuenta la pirámide demográfica. El precio del metro cuadrado había pasado a 1990 euros y eran necesarios seis años y medio de los ingresos de un hogar para comprar una vivienda (Tudela Flores, 2014).

En 2011 el stock de viviendas sin vender era de unos 5000 000, todas ellas construidas entre 2000 y 2008. En estas mismas fechas el precio de la vivienda aún estaba sobrevalorado en un 43,7 \%, y habían pasado tres años desde que estallara la crisis (Tamames, 2011). 
No se trata de dar una serie de cifras más o menos impactantes sobre la crisis que estalló en los años 2007 y 2008 en España, ni relacionarla con la crisis de los EE. UU y sus subprime, ni analizar sus efectos sobre las estructuras bancarias españolas. No es el objetivo de este artículo. La crisis provocada en España por el estallido de la burbuja inmobiliaria y el endeudamiento del Estado se llevó por delante muchos ahorros y esperanzas y también buena parte del Estado del Bienestar español.

La suma de varios factores: paro, recortes en sanidad, recortes en prestaciones sociales, confiscación de pagas extraordinarias a los empleados públicos, recortes en becas, financiación bancaria y, en general, retrocesos en casi todos los avances sociales, desmontó buena parte de las estructuras del bienestar social.

El paro disminuyó por primera vez por debajo del $15 \%$ en el tercer trimestre del 2018, algo que no ocurría desde finales de 2008. No obstante, existen 3326000 personas en situación de desempleo.

Muy probablemente el montaje que, en los primeros años del siglo XXI, con un desarrollo desbocado y unas perspectivas de futuro espectaculares, se había realizado con el Estado del Bienestar era insostenible en una situación de crisis. Quizás también lo fuera en una situación de escaso desarrollo. Gran parte de las prestaciones que se otorgaron en estos años fueron con cargo al déficit del Estado.

Las consecuencias de la crisis inmobiliaria y bancaria que llevaron a la actual situación, no es la única causa de la debacle tanto económica como del sistema de bienestar social que se había edificado en España. El sistema era difícilmente sostenible y ni siquiera en los mejores años del boom económico pudo sostenerse sin recurrir a la financiación exterior a través del déficit. Dicho de otra manera, el Estado de Bienestar español era en sí mismo deficitario. España no podía sostenerlo durante mucho tiempo. Cierto que no es España el país de la UE que más invierte en el EB, ni mucho menos, y también es cierto que es uno de los peor financiados, pero en algunos aspectos es de los mejores, sino el mejor, por ejemplo, en sanidad. Los recortes han sido en general mayores que en otros países de la UE, especialmente los centrales y septentrionales. Pero el Estado del Bienestar es un derecho posibilista.

A pesar de no tener un gasto social per cápita como otros países con mayores posibilidades económicas, tiene uno de los sistemas de seguridad social, con las listas de espera incluidas, de los mejores del mundo. Y unas prestaciones por jubilación muy altas en relación con lo cotizado por cada uno a lo largo de su vida como contribuyente. Que en otros países dediquen más fondos a la seguridad social, a la universidad o a la sanidad, no implica que España deba dar los mismos servicios. Se trata de una cuestión de poder o no (Rodríguez, 2004). 
Es absolutamente cierto que España sufre un déficit social, pero quizás el problema no esté en el enfrentamiento entre fuerzas conservadoras y progresistas, ni desde luego en la mala distribución de la riqueza nacional, sino que esta riqueza no llega para fundamentar y mantener un Estado de Bienestar que satisfaga a todos. No se trata del derecho a estar satisfecho con el Estado de Bienestar sino de poder financiarlo (Macías, 2014).

\section{Reestructuración del Estado del Bienestar}

En primer lugar, es necesario preguntarse si es cierto que el gobierno ha desmantelado el Estado de Bienestar. Y la respuesta, aunque afirmativa, ha de ser matizada. En realidad, lo que ha ocurrido en los últimos años a consecuencia de la crisis ha sido una reestructuración del Estado del Bienestar (Vázquez, Albarrán y Salinas, 2013), pero con una fuerte reducción del bienestar, que es lo mismo que una reducción de prestaciones de todo tipo, desde las sociales a las sanitarias, desde las destinadas a la tercera edad hasta las becas universitarias.

Esta reestructuración se ha realizado en dos campos a la vez: el cuantitativo y el cualitativo. Respecto al cuantitativo se han reducido las prestaciones y las personas que las reciben, además de dilatarse los pagos de dichas prestaciones, de tal manera que no son pocas las personas dependientes que cuando las reciben ya han muerto. Por otra parte, se ha rebajado el nivel cualitativo del bienestar social, especialmente con la carga que las familias han recibido al tener que hacerse cargo de los ancianos, sean dependientes o no, y de los jóvenes que no pueden, por diversas causas, emanciparse (Vázquez, Albarrán y Salinas, 2013).

La retirada de fondos del gasto social y en aquellos subsectores de los gastos sanitarios que inciden directamente en la sociedad, esencialmente las dependencias y los mayores, ha proporcionado fuertes tensiones sociales y repercutido negativamente en el Estado de Bienestar, con mucha probabilidad más que otros cambios estructurales que realizó el gobierno en función de la situación económica.

Respecto al déficit público hay que señalar que, según los datos reportados por el Programa de Estabilidad 2018-2021, España dejará de tenerlo en 2021, si bien, la deuda pública no mermará del 90 \% hasta dicho año. El programa de estabilidad ha referido que: 
En 2021, la deuda pública se prevé que se sitúe en el 89,1 \% del PIB, lo que supone una reducción de más de nueve puntos en cuatro años, contribuyendo de este modo a la corrección de uno de los principales desequilibrios macroeconómicos que presenta la economía española. (Programa de Estabilidad 2018-2021, p. 59).

Por último, hay que señalar que es importante hacer una reflexión sobre la crisis del Estado de Bienestar que ha llevado a una retirada o abandono de sus responsabilidades y ha traspasado las mismas al tercer sector. Éste que, debido al vacío y devastación dejado por el Estado de Bienestar, se ha ido incrementando para poder asumir más responsabilidades de las que le corresponden. En este sentido, Cortina hace la siguiente reflexión:

\footnotetext{
El llamado "Estado del bienestar" ha confundido, a mi juicio, la protección de derechos básicos con la satisfacción de deseos infinitos, medidos en términos del "mayor bienestar del mayor número". Peroconfundir lajusticia, que es un ideal de la razón, con el bienestar, que lo es de la imaginación, es un error por el que podemos acabar pagando un alto precio: olvidar que el bienestar ha de costeárselo cada quien a sus expensas, mientras que la satisfacción de los derechos básicos es una responsabilidad social de justicia, que no puede quedar exclusivamente en manos privadas, sino que sigue haciendo indispensable un nuevo Estado social de derecho -un Estado de justicia, no de bienestar- alérgico al megaestado, alérgico al "electorerismo", y consciente de que debe establecer unas nuevas relaciones con la sociedad civil (Cortina, 1997, p. 87).
}

\section{Conclusiones}

No trata este artículo de buscar la causa de la reducción del Estado del Bienestar, sino de ver cómo puede reinvertirse una tendencia, casi una inercia, para que el gobierno pueda reiniciar el Estado de Bienestar antes de que desaparezcan avances sociales establecidos hace décadas.

Cierto que existe un doble problema. Por un lado, la financiación del Estado del Bienestar que, como ya se ha dicho, produce un déficit imposible de soportar a largo plazo. Por otro, el problema entre el neoliberalismo y las posiciones socialistas sobre la conceptualización del Estado del Bienestar. En este momento, las primeras 
tendencias son las que se están imponiendo, confiando la solución al mercado, lo cual significa que las políticas sociales deben estar subordinadas a la economía. La segunda se fundamenta en las necesidades: el gobierno debe cubrir las necesidades de la ciudadanía.

En el presente, la sociedad contempla cómo va envejeciendo, cada año la pirámide demográfica va ensanchándose por la cúspide y adelgazando por la base. Ve cómo la juventud no tiene trabajo y es la familia quien les protege. Ve cómo los empleos son precarios y los sueldos se reducen. La sociedad ve, asimismo, como el Estado del Bienestar se diluye.

Los recortes y la paulatina reducción de las transferencias sociales han sido en todos los sistemas públicos del Estado del Bienestar, si bien, es la ciudadanía la que más se ha visto afectada. Es necesario que el gobierno afronte los problemas para revertir la situación e incrementar los recursos consignados a transferencias sociales en Estado de Bienestar. Garantizar el derecho a la redistribución de la riqueza, llevando a cabo políticas fiscales progresistas y proporcionales, conforme a la renta y patrimonio de cada ciudadano es una de las principales medidas a desarrollar, así como políticas para la creación de empleo y otro de los componentes clásicos del Estado de Bienestar, el acceso a una vivienda digna, algo que en España ha sido una tarea ardua desde hace años. El problema es cómo puede desarrollarse esta reestructuración, cuáles serán sus límites y cómo financiarse en una sociedad, la española en este caso, con problemas de liquidez, una enorme deuda exterior y con un déficit que aún no ha logrado anularse. Existen dos posibilidades de actuación: en función de la economía y en función de las necesidades. En España se suma, la perspectiva de un envejecimiento de la población que implica el problema adicional de financiación de los derechos pasivos.

En un futuro próximo es difícil, en España, ver una recuperación del Estado de Bienestar, la capacidad de endeudamiento de España está en sus límites. En octubre de 2018, la deuda pública era de 1160976 millones de euros ${ }^{15}$, aun cuando, de momento, es capaz de asumir sus pagos. Sin embargo, la UE avisa del riesgo que supone la elevada deuda del país, y que ésta la hace vulnerable ${ }^{16}$. Sólo a medio plazo se ve la posibilidad de que se detenga la reestructuración negativa del Estado de Bienestar y se establezca un nivel de bienestar, por supuesto, por debajo del que se conoció en la

15 Se puede ampliar información en : www.datosmacro.com, diciembre de 2018. Dicha deuda supone el 96,96\% del PIB español.

16 Sobre este particular se puede consultar Telemadrid (2018)

http://www.telemadrid.es/noticias/economia/Bruselas-advierte-Espana-vulnerabilidad-niv el-0-1991800819--20180307012724.html 
primera década del siglo XXI. Recuperar este último nivel no se vislumbra si no es a un plazo tan largo que se pierde en los horizontes visual y temporal.

\section{Referencias}

Aranzadi, D. (1976). Cooperativismo Industrial como Sistema, Empresa y Experiencia. Universidad de Deusto. Bilbao.

Berzosa C. (2003). El Bienestar en la Economía Mundial. En E. Fontela Montes y J. Guzmán Cueva. (Coord.), Economía ética y bienestar social. Ed. Pirámide. Madrid.

Calveiro, P. (2015). Políticas de miedo y resistencias locales. Athenea Digital ,15(4), 35-59.

Cortina, A. (1997). Ciudadanos del mundo. Hacia una teoría de la ciudadanía. Madrid: Alianza Editorial.

Castles, F. (2010). The English-Speaking Countries. In F. Castles, G. Leibfried, J. Lewis, H. Obinger y C. Pierson. (Eds.), The Oxford Handbook of the Welfare State. Oxford: Oxford University Press.

De Paz Báñez, M. A. y Fíntela, E, Sotelo, I. et al. (2003). Mesa redonda: Otro mundo... ¿ ¿es posible? En J. L. Sampedro, A. Rallo Romero, X. Beiras y J. Ma Vidal Villa. Un mundo para todos. Otra globalización es posible. Barcelona: Icaria.

Endara, S. (2015). Apuntes para una economía política de la solidaridad. Cooperativismo y Desarrollo, 23(107), 23-36.

Esping-Andersen, G. (2001). Fundamentos sociales de las economías postindustriales. Barcelona: Ariel.

Ferrari, L. y Cebey, M. C. (2006). Nuevas formas de acción política: el caso de las empresas recuperadas por sus propios trabajadores. Athenea Digital, 10, 90-102.

García, J.L. (2004). Identidad compartida, componentes diferenciados. Revista Economistas, 22(102), 4-10.

Gomá, R. etal. (2001). Seminari sobre el tercersector. Barcelona: Generalitat de Catalunya. Secretaría General de Joventut. 
Hicks, A. and Esping A, G. (2005). Comparative and Historical Studies of Public Policy and the Welfare State. In T. Janoski, R. Alford, A. Hick and M. A. Schwartz. The Hanbook of Political Sociology. States, Civil Societies, and Globalization. Cambridge: Cambridge University Press.

López-Cózar, C., Priede T. y Del Arco, J. (2015). La empresa social. Experiencias innovadoras a través del deporte. REVESCO. Revista de estudios cooperativos, 119(3), 107-131. doi: https://doi. org/10.5209/rev_REVE.2015.n119.49069.

Macías V., A. (2014). Crecimiento, desigualdad y pobreza: estado de la cuestión. Revista de economía Institucional, 16(31), 101-126. Recuperado de https://papers.ssrn.com/sol3/papers. cfm?abstract_id $=2536029$

Martínez, D.W. (2013). Estado de Bien Estar. Revista Electrónica de Investigación en Ciencias Económicas, 1(2), 203-229. Recuperado de http://revistacienciaseconomicas.unan.edu.ni.

Ministerio de Administraciones Públicas (2008). La Seguridad Social: estructura y financiación. Madrid. Instituto Nacional de la Administración Pública.

Montagut, T. (2004). Política Social. Madrid: Ariel.

Monzón Campos, J. L. y Chaves Ávila, R. (2012). La Economía social en la Unión Europea. Bruselas: Comité Económico y Social Europeo. Unión Europea.

Navarro Ruvalcaba, Mario Alfredo (2006). Modelos y regímenes de bienestar social en una perspectiva comparativa: Europa, Estados Unidos y América Latina. Desacatos, 21, 109-134. Recuperado de http://www.scielo.org.mx/pdf/desacatos/n21/n21a8.pdf

Pineda, J. et al. (1994). Cooperativismo mundial 150 años. Bogotá, Colombia: Consultamérica Grupo Asesor.

Pino Matute, E. del y Rubio Lara, Ma J. (Ed.) (2013). Los Estados de Bienestar en la encrucijada. Políticas Sociales en perspectiva comparada. Madrid: Tecnos.

Programa de Estabilidad 2018-2021 (2018). Actualización del programa de estabilidad y del plan presupuestario. Recuperado de: http://www.mineco.gob.es/stfls/mineco/comun/ pdf/180503_np_estabilidad.pdf

Rodríguez, G. (2004). El Estado de Bienestar en España: Debates, desarrollo y retos. Madrid: Fundamentos. 
Tamames, R. (2011). ¿Cuándo y cómo acabará la crisis? Madrid: Turpial.

Tortuero, J.Ly Águila, O. (2004). Los sistemas de pensiones en Europa y Latinoamérica: realidades, expectativas e ideas para un debate. Revista del Ministerio de Trabajo y Asuntos Sociales, 54.

Tudela Flores, A. (2014). Crisis S.A. El saqueo neoliberal. Madrid: Akal.

Vázquez, J.J.; Albarrán Fernández, C. \& Salinas Ramos, F. (2013). La economía social ante el nuevo paradigma de Bienestar social. Ciriec, Revista de economía Pública, Social y Cooperativa, 79, 5-34.

Velasco Criado, D. (2001). Pensamiento político contemporáneo. Segunda edición. Universidad de Deusto, Bilbao. 